\title{
Alternative somatic cell count traits to improve mastitis resistance in Canadian Holsteins
}

\author{
A. Koeck, ${ }^{* 1}$ F. Miglior, †‡ D. F. Kelton, $\S$ and F. S. Schenkel ${ }^{\star}$ \\ *Centre for Genetic Improvement of Livestock, University of Guelph, Guelph, Ontario, Canada, N1G 2W1 \\ †Guelph Food Research Centre, Agriculture and Agri-Food Canada, Guelph, Ontario, Canada, N1G 5C9 \\ ¥Canadian Dairy Network, Guelph, Ontario, Canada, N1K 1E5 \\ $\S$ Department of Population Medicine, Ontario Veterinary College, University of Guelph, Guelph, Ontario, Canada, N1G 2W1
}

\begin{abstract}
The objective of this study was to investigate whether alternative somatic cell count (SCC) traits are suitable as mastitis indicators in Canadian Holsteins. Mastitis data recorded by producers were available from the national dairy cattle health system in Canada. Mastitis was defined as a binary variable based on whether or not the cow had at least one mastitis case in the period from calving to $305 \mathrm{~d}$ after calving. The analyzed alternative SCC traits included mean somatic cell score (SCS) from different time periods, maximum SCS, standard deviation of SCS, excessive test-day SCC, and a peak pattern of test-day records with suspicion of mastitis. Data of 53,626 first-lactation Holstein cows from 1,666 herds across Canada were analyzed using linear animal models. A heritability of 0.02 was obtained for mastitis. For both mean SCS in early and late lactation, a heritability of 0.11 was estimated. Heritabilities of various patterns of SCC ranged from 0.01 to 0.07 . Estimated genetic correlations were 0.69 and 0.68 between mastitis and mean SCS in early and late lactation, respectively. Higher genetic correlations were found between mastitis and the different SCC patterns $(0.82$ to 0.91$)$. Sires with high breeding values for mastitis resistance had consistently higher percentage of healthy daughters than sires with low breeding values for mastitis resistance. Breeding values for mean SCS in early lactation, standard deviation of SCS, and an excessive test-day SCC pattern (at least one SCC test-day above 500,000) were the best predictors of the breeding value for mastitis resistance and explained in total $41 \%$ of the variation in relative breeding values for mastitis resistance. The results demonstrated that patterns of SCC provide additional information for genetic evaluations of mastitis resistance that cannot be explained by mean SCS alone.
\end{abstract}

Received July 14, 2011.

Accepted September 15, 2011

${ }^{1}$ Corresponding author: akoeck@uoguelph.ca
Key words: mastitis, somatic cell count pattern, genetic correlation

\section{INTRODUCTION}

Mastitis, an inflammation of the mammary gland, is one of the most frequent and costly diseases of dairy cattle. In the Scandinavian countries, direct selection for improved mastitis resistance based on veterinary treatments has been carried out for more than $30 \mathrm{yr}$ (Philipsson and Lindhé, 2003). In recent years, great efforts have been made to establish disease-recording systems in some other countries (e.g., in Austria; Egger-Danner et al., 2007). In Canada, a national dairy cattle health and disease data management system was started in 2007. Eight specific diseases that are known to affect herd profitability are recorded by producers on a voluntary basis: mastitis, lameness, cystic ovarian disease, displaced abomasum, ketosis, metritis, milk fever, and retained placenta. A survey to assess the recording practices of Canadian dairy producers revealed that mastitis is the most frequently recorded disease (Neuenschwander, 2010). This reflects also the high economic importance of this trait.

As disease-recording systems are not widely implemented, lactation-mean SCS or test-day SCS are most commonly used as mastitis indicators. Recently, other traits that are derived from SCC have been suggested as alternatives to improve genetic evaluations for mastitis resistance. Distribution characteristics of test-day SCC have been analyzed by Green et al. (2004). Their results indicated that using measures of variation (e.g., standard deviation of SCC) and maximum cow SCC would enhance the accuracy of predicting clinical mastitis, compared with mean SCC. de Haas et al. (2008) used excessive test-day SCC and peak patterns to describe the dynamic nature of a mastitis case better. The number of days of increased SCC during lactation has been identified as another promising trait to increase mastitis resistance in dairy cattle (Urioste et al., 2010).

The objective of this study was to use mastitis data from the national dairy cattle health system in Can- 
ada to investigate whether alternative SCC traits are feasible as mastitis indicators in Canadian Holsteins. Alternative SCC traits include mean SCS from different time periods, maximum SCS, standard deviation of SCS, excessive test-day SCC, and a peak pattern of test-day records with suspicion of mastitis.

\section{MATERIALS AND METHODS}

\section{Data}

Mastitis data recorded by dairy producers from April 2007 to January 2011, as well as test-day records of SCC between 5 and 305 DIM, were obtained from the Canadian Dairy Network (Guelph, Ontario, Canada). To ensure that all cows were from herds with reliable mastitis recording, only herds having at least 2 recorded mastitis cases within the study period were considered. The first and last mastitis case had to be at least 180 $\mathrm{d}$ apart for not removing a herd from the analysis, otherwise it would be considered to have health recording for just a short period. In addition, a minimum mastitis frequency of $5 \%$ per herd and year was applied to ensure continuous data recording. After all of the described editing to ensure reliable documentation and recording, about $47 \%$ of all herds were excluded.

Only first-lactation Holstein cows with an age between 19 and 43 mo were considered. Moreover, only cows with information for all alternate traits were included. The data set was restricted further to include only cows from herd-year classes with at least 3 first-lactation cows. The final data set consisted of records from 53,626 first-lactation Holstein cows, from 1,666 herds. The animal pedigree file was generated by tracing the pedigrees of cows 7 generations back. The resulting pedigree file contained the relationship of 260,634 animals.

\section{Definition of Traits}

In Canada, clinical mastitis cases are recorded by producers. Mastitis is defined as visually abnormal milk (e.g., clots, flakes, or watery) from one or more quarters, that may also include inflammation of the udder (e.g., heat, swelling, or discoloration) and systemic illness of the cow. For genetic analyses, mastitis was defined as a binary trait $(0=$ no mastitis, $1=$ mastitis $)$ based on whether or not the cow had at least one mastitis case in the period from calving to $305 \mathrm{~d}$ after calving.

Seven alternative SCC traits were defined as mastitis indicators for genetic evaluation. Test-day SCC was $\log _{2}$ transformed to SCS and averaged over early (5 to 150 DIM, SCS150) and late (151 to 305 DIM, SCS151-305) lactation. Green et al. (2004) showed that maximum and standard deviation $\log$ SCC were better indicators of mastitis than mean log SCC. Thus, the traits maximum SCS (SCSMAX) and standard deviation of SCS during lactation (SCSSD) were investigated. A minimum of 3 test-day records were required to calculate SCSMAX and SCSSD for each animal. Excessive test-day SCC is an indication of an inflammation of the mammary gland. Thus, 2 traits with different thresholds were defined: TD > 200 considered cows with at least one SCC test-day above $500,000,300,000$, and 200,000 cells $/ \mathrm{mL}$ within 5 to 10 DIM, 11 to 30 DIM, and 31 to 305 DIM, respectively, as infected (1), otherwise as healthy (0). Different thresholds during lactation were chosen to account for fluctuations due to DIM. The thresholds and time periods were based on the average lactation curve for SCC from cows with at least one mastitis case during lactation (Figure 1). Presence or absence of TD >500 was scored as 1 or 0 , based on whether or not the cow had at least one SCC test-day above 500,000 cells/mL during lactation. The threshold is based on Figure 2, which shows the pattern of SCC before and after the first mastitis case. This figure shows that infected cows had an SCC above 500,000 cells $/ \mathrm{mL}$ during the peak of infection. A peak pattern was used to identify short periods of increased SCC (PK) during lactation; PK was defined as a binary trait $(0=$ no peak, $1=$ peak $)$ based on whether or not the cow had at least one peak with the pattern low-high-low. Based on Figure 2, healthy and recovered cows were assumed to have $\leq 500,000$ cells/ $\mathrm{mL}$ (low SCC), whereas infected cows were assumed to have $>500,000$ cells $/ \mathrm{mL}$ (high SCC). A minimum of 3 test-day records were required to calculate PK.

\section{Models}

Data were analyzed with univariate and bivariate linear animal models using the average information restricted maximum likelihood (AI-REML) procedure in the derivative-free approach to multivariate analysis (DMU) package (Madsen and Jensen, 2008). Although threshold models are, at least in theory, more appropriate to analyze binary traits, linear models were applied. In previous studies, linear models were found to be robust toward departures from normality and performed equally well as threshold models (e.g., Koeck et al., 2010). Besides, genetic correlations are reported to be correct for binary traits using linear models (e.g., Negussie et al., 2008).

Univariate Linear Model. The following linear animal model was applied to all traits:

$$
\mathbf{y}=\mathbf{X} \boldsymbol{\beta}+\mathbf{Z}_{\mathbf{h}} \mathbf{h}+\mathbf{Z}_{\mathrm{a}} \mathbf{a}+\mathbf{e}
$$

where $\mathbf{y}$ is a vector of observations for mastitis, SCS150, SCS151-305, SCSMAX, SCSSD, TD >200, TD >500, 


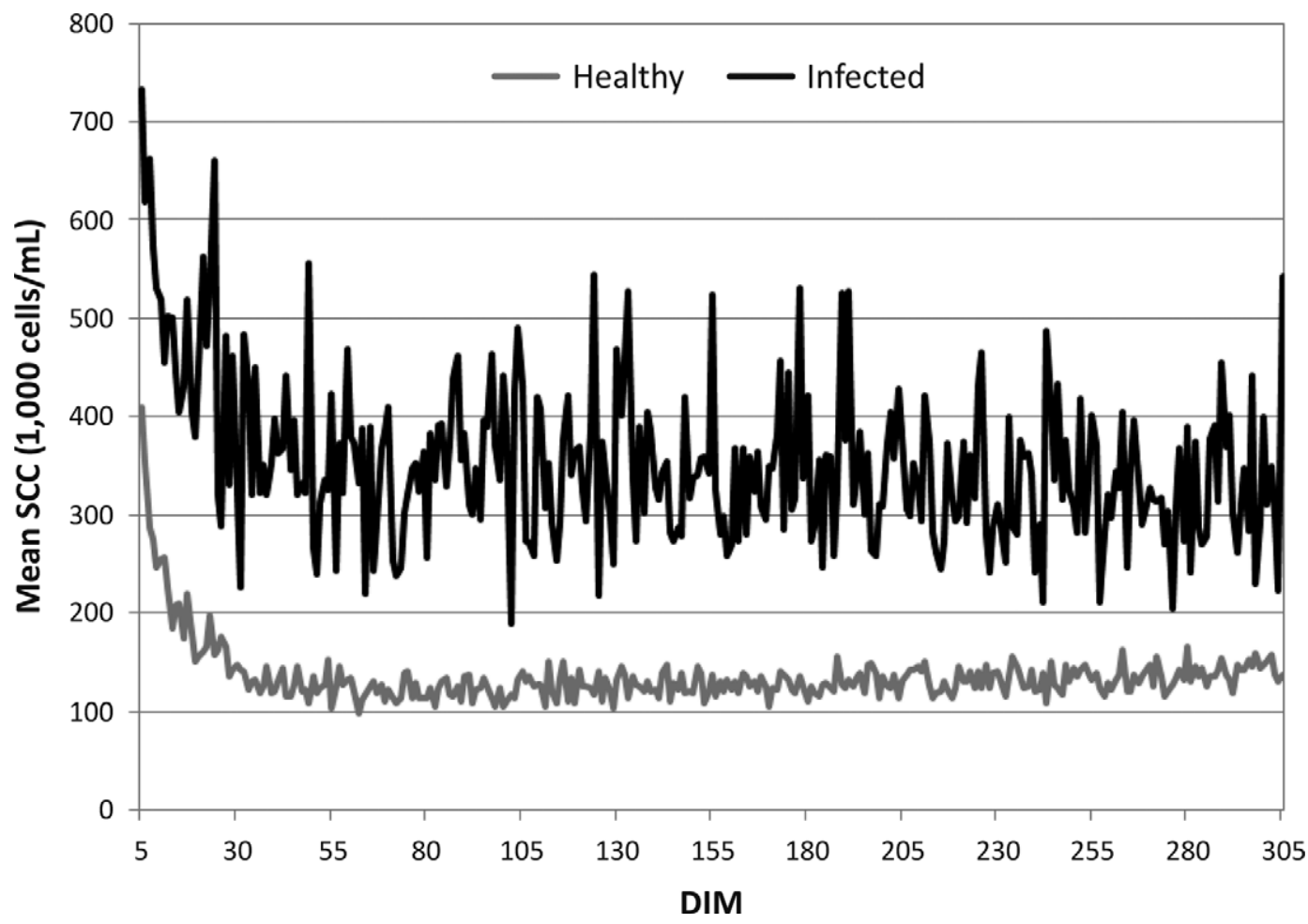

Figure 1. Mean SCC by stage of lactation for healthy and infected cows with at least one mastitis case during lactation.

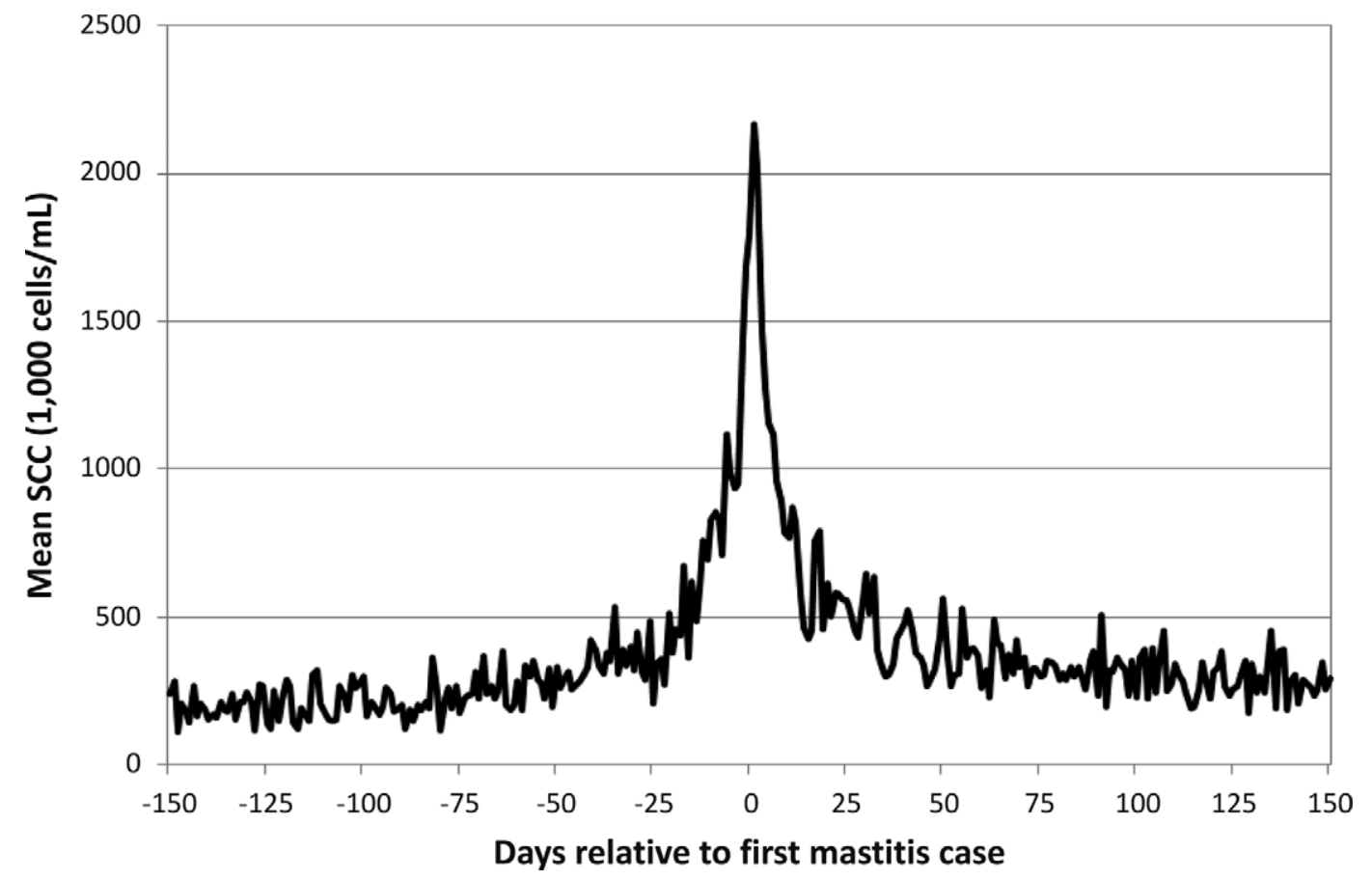

Figure 2. The pattern of mean SCC before and after the first mastitis case. 
or PK; $\boldsymbol{\beta}$ is a vector of systematic effects, including fixed effects of age at calving (16 classes) and yearseason of calving (11 classes); $\mathbf{h}$ is a vector of random herd-year of calving effects (3,322 levels); $\mathbf{a}$ is a vector of random animal effects $(260,634$ levels); e is a vector of random residuals; and $\mathbf{X}, \mathbf{Z}_{\mathrm{h}}$, and $\mathbf{Z}_{\mathrm{a}}$ are the corresponding incidence matrices. Age at first calving had 16 classes, in which $<22$ and $>35$ mo were the first and last classes, respectively, and other classes were single months. Year-seasons of calving classes, from April 2007 to November 2009, were formed by combining 3 mo (January-March, April-June, July-September, and October-December).

Random effects were assumed to be normally distributed with zero means and the covariance structure was

$$
\operatorname{Var}\left[\begin{array}{l}
h \\
a \\
e
\end{array}\right]=\left[\begin{array}{ccc}
\mathbf{I} \sigma_{h}^{2} & 0 & 0 \\
& \mathbf{A} \sigma_{a}^{2} & 0 \\
\text { symm. } & \mathbf{I} \sigma_{e}^{2}
\end{array}\right],
$$

where $\sigma_{h}^{2}, \sigma_{a}^{2}$, and $\sigma_{e}^{2}$ are the herd-year, animal, and residual variances, respectively; $\mathbf{I}$ is an identity matrix; and $\mathbf{A}$ is the additive genetic relationship matrix.

Bivariate Linear Model. Bivariate linear animal models were carried out for each combination of 2 traits considered in the present study. Fixed and random effects were as in the univariate model. Random effects were assumed to be normally distributed with zero means and the covariance structure was

$$
\operatorname{Var}\left[\begin{array}{c}
h \\
a \\
e
\end{array}\right]=\left[\begin{array}{ccc}
\mathbf{H}_{0} \otimes I & 0 & 0 \\
& \mathbf{G}_{0} \otimes \mathbf{A} & 0 \\
\text { symm. } & & \mathbf{R}_{0} \otimes \mathbf{I}
\end{array}\right],
$$

where $\mathbf{H}_{0}=\left[\begin{array}{ll}\sigma_{h 1}^{2} & \sigma_{h 1 h 2} \\ \sigma_{h 1 h 2} & \sigma_{h 2}^{2}\end{array}\right]$ is the (co)variance matrix between traits due to herd-year of calving effects; $\mathbf{I}$ is an identity matrix; $\mathbf{G}_{0}=\left[\begin{array}{cc}\sigma_{a 1}^{2} & \sigma_{a 1 a 2} \\ \sigma_{a 1 a 2} & \sigma_{a 2}^{2}\end{array}\right]$ is the (co)variance matrix between traits due to animal additive genetic effects; $\mathbf{A}$ is the additive genetic relationship matrix; and $\mathbf{R}_{0}=\left[\begin{array}{cc}\sigma_{e 1}^{2} & \sigma_{e 1 e 2} \\ \sigma_{e 1 e 2} & \sigma_{e 2}^{2}\end{array}\right]$ is the (co)variance matrix between traits due to residual effects. Heritability estimates were calculated as the mean estimate from all bivariate analyses for each trait.

\section{Prediction of Breeding Values}

Breeding values of sires with at least 30 daughters for all traits were predicted from univariate analyses.
Estimated breeding values were standardized to relative breeding values (RBV) with a mean of 100 and a standard deviation of 5 and reversed in sign. Thus, higher RBV indicate sires with daughters more resistant to mastitis and lower SCC.

Multiple linear regression analyses using the PROC REG procedure of SAS version 9.2 (SAS Institute, 2008) were performed, where RBV of alternative SCC traits were included as independent variables. The backward elimination and Mallows' $C_{p}$ model selection methods were used to find the combination of alternative SCC traits that best predict the RBV for mastitis resistance. All variables left in the backward elimination selection method were significant at the $5 \%$ level.

\section{RESULTS AND DISCUSSION}

\section{Phenotypic Analysis}

In the present study, mastitis frequency in firstlactation Holstein cows was $12.7 \%$ within $305 \mathrm{~d}$ after calving, which is in the lower range of previous Canadian studies. In 65 dairy farms located in Ontario, Sargeant et al. (1998) reported a mastitis frequency of $16.5 \%$ in first-lactation cows. van Dorp et al. (1999) found a much lower mastitis incidence rate of $5.6 \%$ in first-lactation Holstein cows based on farm records of 32 herds in British Columbia. In more recent studies in 48 Ontario dairy farms and 116 dairy herds in 10 provinces of Canada, the lactation incidence rate of mastitis over all lactations was estimated to be 22 and $23 \%$, respectively (McLaren et al., 2006; Olde Riekerink et al., 2008). The lower mastitis frequency found in the present study may be caused by underreporting of mastitis cases. The other studies mentioned were based on a limited number of herds, which possibly had done health recording more accurately. As reported in previous studies (e.g., Sargeant et al., 1998), the majority of mastitis cases occurred in early lactation (Table 1), when cows were facing high physiological demands.

The lactation curve for mean SCC from cows with mastitis showed a similar shape as for healthy cows, but SCC from infected cows was higher throughout the lactation (Figure 1). The mean SCC of infected cows before the first mastitis case was already on a higher level at around 250,000 cells/mL and remained quite high after the mastitis case (Figure 2). Producers in Canada are recording mastitis events, but not the pathogen that is causing the infection. Thus, Figure 1 and Figure 2 represent the effect of all present pathogens on the lactation curve for SCC. de Haas et al. (2002) showed that mastitis caused by different pathogens affects the lactation curve for SCC differently. For example, SCC was low before a case of Escherichia coli 
Table 1. Occurrence of first incidence of mastitis by stage of lactation (percentage of mastitis cases in each interval)

\begin{tabular}{lc}
\hline $\begin{array}{l}\text { Days } \\
\text { after calving }\end{array}$ & $\begin{array}{c}\% \text { of mastitis } \\
\text { cases }(\mathrm{n}=6,824)\end{array}$ \\
\hline $0-30$ & 32.7 \\
$31-60$ & 9.4 \\
$61-90$ & 8.6 \\
$91-120$ & 8.3 \\
$121-150$ & 8.3 \\
$151-180$ & 7.9 \\
$181-210$ & 6.9 \\
$211-240$ & 6.4 \\
$241-270$ & 6.1 \\
$271-305$ & 5.4 \\
\hline
\end{tabular}

mastitis and decreased rapidly after the infection to a level only slightly higher than the level before infection. In contrast, an increase in SCC was observed before a clinical case of Staphylococcus aureus mastitis, which suggests that the pathogen is subclinically present before clinical symptoms are observed. In addition, SCC remained high after the case of Staphylococcus aureus mastitis.

One potential shortcoming of using SCC as an indicator trait for mastitis resistance is that the detection of clinical mastitis events with rapid recovery may be difficult, because SCC is often recorded at approximately monthly intervals. Indeed, only $45 \%$ of all infected cows in the present study had at least one test-day record for SCC within $10 \mathrm{~d}$ before to $10 \mathrm{~d}$ after the infection. This shows that for a high proportion of the diseased cows, the infection peak will not be recorded.

The phenotypic association between lactation mean SCC and mastitis frequency is shown in Figure 3. Cows with lactation mean SCC lower or equal to 25,000 cells/ $\mathrm{mL}$ had the lowest mastitis frequency (4\%), whereas $38 \%$ of all cows with lactation mean SCC over 500,000 cells $/ \mathrm{mL}$ had at least one mastitis case.

Means of analyzed alternative SCC traits in firstlactation cows with and without mastitis are shown in Table 2. As expected, diseased cows had higher mean for SCS150, SCS151-305, SCSMAX, and SCSSD and higher frequency of TD $>200$, TD $>500$, and PK.

\section{Genetic Parameter Estimation}

Estimates of heritability and genetic correlations from bivariate analyses are given in Table 3 . The heritability of mastitis was 0.02 . This estimate is in accordance with results from previous studies using linear models, with most values in the interval from 0.02 to 0.03 (e.g., Heringstad et al., 2000).

For both SCS150 and SCS151-305, a heritability of 0.11 was estimated, which also agrees with previous analyses from de Haas et al. (2008) and Urioste et al. (2010).

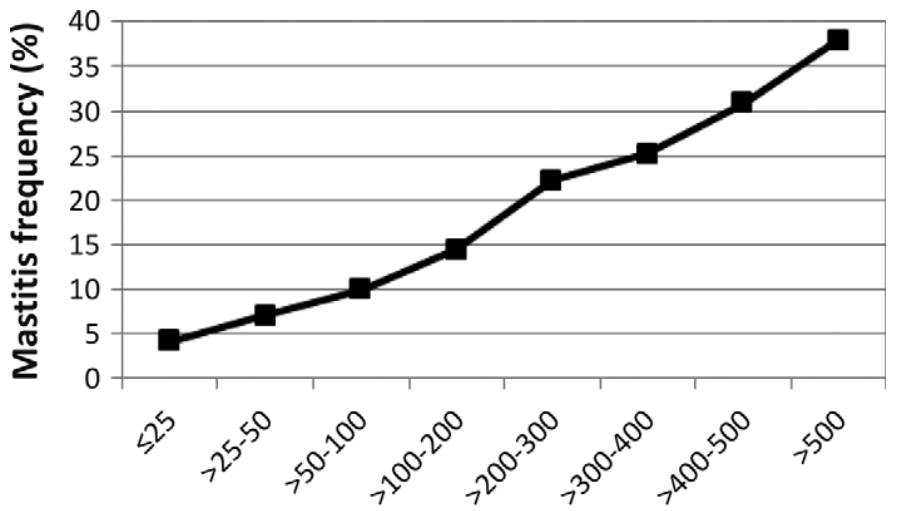

Lactation mean SCC (1,000 cells $/ \mathrm{mL})$

Figure 3. Association between lactation mean SCC (5 to 305 DIM) and mastitis frequency.

Estimated heritabilities of SCSMAX and SCSSD were 0.07 and 0.03 , respectively. Maximum SCS has never been investigated in genetic studies, whereas Urioste et al. (2010) reported a higher heritability of 0.10 for standard deviation of SCC from monthly test-day records.

Heritabilities of TD $>200$, TD $>500$, and PK were $0.05,0.03$, and 0.01 , respectively. Based on a linear model, de Haas et al. (2008) found a heritability of 0.06 for absence or presence of test-day SCC exceeding 150,000 cells/mL. For TD >500, Urioste et al. (2010) obtained a heritability of 0.12 using a threshold model. No previous heritability estimates of the trait PK were found in the literature. However, de Haas et al. (2008) analyzed number of peaks and found heritabilities in the range of 0.01 to 0.05 .

Table 2. Mean SCS150, SCS151-305, SCSMAX, SCSSD, and frequencies of TD $>200$, TD $>500$, and PK for cows with absence (0) or presence (1) of mastitis

\begin{tabular}{lccc}
\hline & & \multicolumn{2}{c}{ Mastitis } \\
\cline { 3 - 4 } Trait & $\begin{array}{c}\text { Overall } \\
\text { mean }\end{array}$ & 0 & 1 \\
\hline SCS150 $\left(\log _{2}\right)$ & 2.1 & 2.0 & 2.8 \\
SCS151-305 $\left(\log _{2}\right)$ & 2.2 & 2.1 & 3.0 \\
SCSMAX $\left(\log _{2}\right)$ & 3.9 & 3.7 & 5.3 \\
SCSSD $\left(\log _{2}\right)$ & 1.0 & 0.9 & 1.4 \\
TD $>200(\%)$ & 37.4 & 33.1 & 66.5 \\
TD $>500(\%)$ & 21.7 & 17.6 & 50.2 \\
PK $(\%)$ & 10.4 & 8.4 & 23.7 \\
\hline
\end{tabular}

${ }^{1}$ SCS150 $=$ test-day SCS averaged between 5 and 150 DIM; SCS151305 = test-day SCS averaged between 151 and 305 DIM; SCSMAX $=$ maximum SCS; SCSSD = standard deviation of SCS; TD $>200$ $=$ presence of at least one SCC test-day above 500,000,300,000, and 200,000 cells $/ \mathrm{mL}$ within 5 to 10 DIM, 11 to 30 DIM, and 31 to 305 DIM, respectively; TD $>500=$ presence of at least one SCC test-day above 500,000 cells $/ \mathrm{mL}$; PK $=$ presence of at least one peak with the SCC pattern low-high-low (low: $\leq 500,000$ cells/mL, high: $>500,000$ cells $/ \mathrm{mL}$ ). 
Table 3. Heritabilities (on the diagonal) and genetic correlations (above the diagonal) for mastitis and alternative SCC traits (SCS150, SCS151305, SCSMAX, SCSSD, TD >200, TD >500, and PK) ${ }^{1}$ with standard errors in parentheses from bivariate analyses

\begin{tabular}{|c|c|c|c|c|c|c|c|c|}
\hline Trait & Mastitis & SCS150 & SCS151-305 & SCSMAX & SCSSD & $\mathrm{TD}>200$ & $\mathrm{TD}>500$ & PK \\
\hline Mastitis & $0.02(0.005)$ & $0.69(0.08)$ & $0.68(0.07)$ & $0.85(0.05)$ & $0.82(0.07)$ & $0.84(0.06)$ & $0.85(0.06)$ & $0.91(0.09)$ \\
\hline SCS150 & & $0.11(0.011)$ & $0.93(0.02)$ & $0.93(0.02)$ & $0.29(0.10)$ & $0.93(0.02)$ & $0.88(0.04)$ & $0.82(0.10)$ \\
\hline SCS151-305 & & & $0.11(0.011)$ & $0.93(0.02)$ & $0.31(0.10)$ & $0.94(0.02)$ & $0.91(0.03)$ & $0.94(0.06)$ \\
\hline SCSMAX & & & & $0.07(0.009)$ & $0.60(0.07)$ & $0.99(0.01)$ & $0.99(0.01)$ & $0.96(0.05)$ \\
\hline SCSSD & & & & & $0.03(0.006)$ & $0.53(0.09)$ & $0.66(0.08)$ & $0.65(0.13)$ \\
\hline $\mathrm{TD}>200$ & & & & & & $0.05(0.007)$ & $1.00(0.01)$ & $0.96(0.05)$ \\
\hline $\mathrm{TD}>500$ & & & & & & & $0.03(0.006)$ & $0.97(0.04)$ \\
\hline PK & & & & & & & & $0.01(0.002)$ \\
\hline
\end{tabular}

${ }^{1}$ SCS150 = test-day SCS averaged between 5 and 150 DIM; SCS151-305 = test-day SCS averaged between 151 and 305 DIM; SCSMAX = maximum SCS; SCSSD = standard deviation of SCS; TD > 200 = presence of at least one SCC test-day above 500,000, 300,000, and 200,000 cells/ $\mathrm{mL}$ within 5 to $10 \mathrm{DIM}, 11$ to $30 \mathrm{DIM}$, and 31 to $305 \mathrm{DIM}$, respectively; TD $>500=$ presence of at least one SCC test-day above 500,000 cells $\mathrm{mL} ; \mathrm{PK}=$ presence of at least one peak with the SCC pattern low-high-low (low: $\leq 500,000$ cells $/ \mathrm{mL}$, high: $>500,000 \mathrm{cells} / \mathrm{mL}$ ).

Genetic correlations between mastitis and SCS150 and between mastitis and SCS151-305 were 0.69 and 0.68 , respectively. Although the proportion of mastitis cases is much higher in the first part of lactation, genetic correlations between mastitis and SCS150 were not higher than between mastitis and SCS151-305. In contrast, de Haas et al. (2008) and Bloemhof et al. (2009) found slightly higher genetic correlations between mastitis and mean SCS in the first half of lactation, than between mastitis and mean SCS in the second half of lactation.

Genetic correlations in the range of 0.82 and 0.91 were found between mastitis and SCSMAX, SCSSD, TD $>200$, TD > 500, and PK. Therefore, these traits tended to show stronger genetic correlations to mastitis than mean SCS (SCS150 and SCS151-305). This indicates that patterns of SCC are more suitable to describe the sudden and drastic changes in SCC resulting from a case of mastitis than mean SCS. de Haas et al. (2008) and Windig et al. (2010) reported lower genetic correlations in the range from 0.60 to 0.75 between mastitis and absence or presence of test-day SCC exceeding 150,000 cells/mL. The chosen threshold of 150,000 cells/mL was, however, maybe too low to differentiate between healthy and infected cows. In both mentioned studies, high genetic correlations were obtained between mastitis and number of peaks, with estimates ranging from 0.66 to 0.93 (de
Haas et al., 2008) and from 0.85 to 0.88 (Windig et al., 2010).

High genetic correlations in the range of 0.82 to 0.94 were found between mean SCS traits and TD >200, TD >500, and PK. The SCSSD showed lower genetic correlations with SCS150 and SCS151-305 (0.29 and 0.31 , respectively). In contrast, genetic correlations between SCSSD and patterns of SCC were higher and ranged from 0.53 to 0.66 . The SCSSD is a measure of variability in SCC during lactation, which may occur because of a mammary infection. Thus, this result indicates that SCSMAX, TD > 200, TD >500, and PK describe variability in SCC during lactation better than mean SCS. This is also reasonable because SCS150 and SCS151-305 are influenced by all SCC records during early and late lactation, respectively. The calculation of mean values will lead to a dilution of peak values because some test-day SCC records are sampled when no mammary infection is present. Genetic correlations among SCSMAX, TD > 200, TD >500, and PK were almost 1 (0.96-1.00).

\section{Prediction of Breeding Values}

Despite the low heritability of mastitis, large differences between daughter groups were observed. As shown in Figure 4, the percentage of healthy daughters varied between 77 and $92 \%$ among the 10 sires with

Table 4. Best predictors of relative breeding value for mastitis resistance based on the backward elimination model selection method

\begin{tabular}{lrccc}
\hline Item $^{1}$ & Estimate & $\mathrm{SE}$ & $P$-value & $\mathrm{R}^{2}$ \\
\hline Intercept & 20.88473 & 7.24504 & 0.0044 & \\
SCS150 & 0.18596 & 0.07850 & 0.0189 & \\
SCSSD & 0.32490 & 0.08942 & 0.0004 & \\
TD $>500$ & 0.26930 & 0.11474 & 0.0200 & 0.41 \\
\hline
\end{tabular}

${ }^{1}$ SCS150 = test-day SCS averaged between 5 and 150 DIM; SCSSD $=$ standard deviation of SCS; TD $>500=$ presence of at least one SCC test-day above 500,000 cells $/ \mathrm{mL}$. 


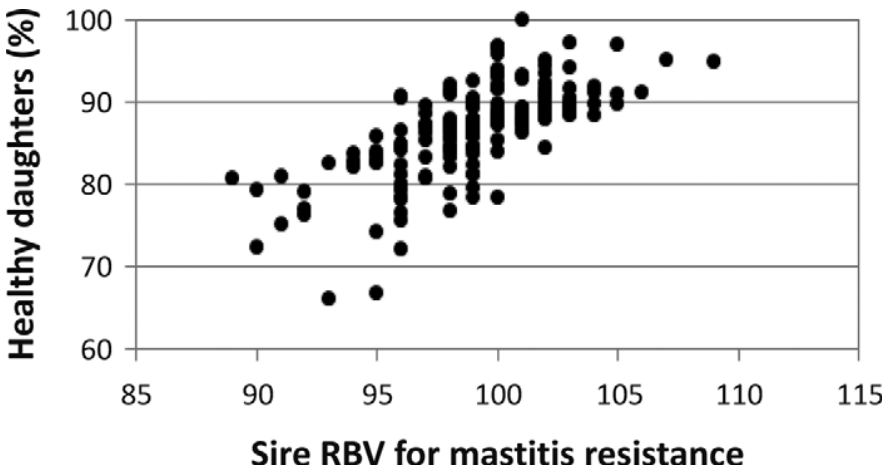

Figure 4. Percentage of healthy daughters according to the relative breeding value $(\mathrm{RBV})$ of mastitis resistance of sires with at least 30 daughters $(\mathrm{n}=180)$.

the worst RBV and the 10 sires with the best RBV for mastitis resistance.

Results from the multiple linear regression analyses are shown in Tables 4 and 5. Both model selection methods (backward elimination and Mallows' $C_{p}$ ) gave the same result. The best predictor of mastitis resistance was a combination of SCS150, SCSSD, and TD $>500$, which explained in total $41 \%$ of the variation in $\mathrm{RBV}$ for mastitis resistance. In comparison, mean SCS in early and late lactation (SCS150 and SCS151-305) explained together only $25 \%$ of the variation in RBV for mastitis resistance. Analyzing the phenotypic relationships, Green et al. (2004) found that maximum and standard deviation of log SCC were the best mastitis indicators. Urioste et al. (2010) defined a large number of alternative SCC traits and used cluster procedures and a stepwise logistic regression to identify SCC traits that were phenotypically more closely associated with mastitis resistance than mean SCC. Similar to our results, standard deviation of SCC and TD >500 were among the most promising traits.

In the present study, the variation in mastitis resistance that can be explained by alternative SCC traits was quite low. A possible explanation is that only 180 sire breeding values were included in the analyses. Besides, given the low heritability of most traits, the accuracies of the breeding values are expected to be low.

Table 5. Best predictors of relative breeding value for mastitis resistance based on the Mallows' $C_{p}$ model selection method

\begin{tabular}{lcc}
\hline Item $^{1}$ & $\mathrm{R}^{2}$ & $C_{p}$ \\
\hline SCS150, SCSSD, TD $>500$ & 0.41 & 2.61 \\
SCS150, SCS151-305 & 0.25 & 48.70 \\
\hline
\end{tabular}

${ }^{1}$ SCS150 $=$ test-day SCS averaged between 5 and 150 DIM; SCSSD $=$ standard deviation of SCS; TD >500 = presence of at least one SCC test-day above 500,000 cells/mL; SCS151-305 = test-day SCS averaged between 151 and 305 DIM.
Nevertheless the results clearly showed that patterns of SCC provide additional information for genetic evaluation of mastitis resistance that cannot be explained by mean SCS.

In Canada, mastitis data are only recorded in a limited number of herds, whereas SCC is collected in all milk-recording herds for a long time. Thus, alternative SCC traits seem promising to improve genetic evaluations of mastitis resistance.

\section{CONCLUSIONS}

The results demonstrated that the data from the Canadian health recording system can be used, together with SCC data, for genetic evaluation of mastitis resistance. Among the various SCC traits, patterns of SCC had lower heritability but stronger genetic correlations with mastitis than mean SCS traits. Breeding values for SCS150, SCSSD, and TD >500 were the best predictors of mastitis resistance, which explained in total $41 \%$ of the variation in RBV for mastitis resistance. Patterns of SCC provide additional information for genetic evaluation of mastitis resistance that cannot be explained by mean SCS.

\section{ACKNOWLEDGMENTS}

All dairy producers recording health data are gratefully acknowledged. This study was funded by the DairyGen council of Canadian Dairy Network (Guelph, Ontario, Canada) and the Natural Sciences and Engineering Research Council of Canada (Ottawa, Ontario, Canada).

\section{REFERENCES}

Bloemhof, S., G. de Jong, and Y. de Haas. 2009. Genetic parameters for clinical mastitis in the first three lactations of Dutch Holstein cattle. Vet. Microbiol. 134:165-171.

de Haas, Y., H. W. Barkema, and R. F. Veerkamp. 2002. The effect of pathogen-specific clinical mastitis on the lactation curve for somatic cell count. J. Dairy Sci. 85:1314-1323.

de Haas, Y., W. Ouweltjes, J. ten Napel, J. J. Windig, and G. de Jong. 2008. Alternative somatic cell count traits as mastitis indicators for genetic selection. J. Dairy Sci. 91:2501-2511.

Egger-Danner, C., B. Fuerst-Waltl, W. Holzhacker, R. Janacek, J. Lederer, C. Litzllachner, C. Mader, M. Mayerhofer, J. Miesenberger, W. Obritzhauser, G. Schoder, and A. Wagner. 2007. Establishing a health monitoring for cattle in Austria: First experiences. Page 363 in Book of abstracts of the 58th Annual Meeting of the EAAP, Dublin, Ireland. Wageningen Academic Publishers, Wageningen, the Netherlands.

Green, M. J., L. E. Green, Y. H. Schukken, A. J. Bradley, E. J. Peeler, H. W. Barkema, Y. de Haas, V. J. Collis, and G. F. Medley. 2004 Somatic cell count distributions during lactation predict clinical mastitis. J. Dairy Sci. 87:1256-1264.

Heringstad, B., G. Klemetsdal, and J. Ruane. 2000. Selection for mastitis resistance in dairy cattle: A review with focus on the situation in the Nordic countries. Livest. Prod. Sci. 64:95-106.

Koeck, A., B. Heringstad, C. Egger-Danner, C. Fuerst, and B. FuerstWaltl. 2010. Comparison of different models for genetic analysis 
of clinical mastitis in Austrian Fleckvieh dual-purpose cows. J. Dairy Sci. 93:4351-4358.

Madsen, P., and J. Jensen. 2008. An User's Guide to DMU. A package for analyzing multivariate mixed models. Version 6 , release 4.7 . Danish Institute of Agricultural Sciences, Tjele, Denmark.

McLaren, C. J., K. D. Lissemore, T. F. Duffield, K. E. Leslie, D. F. Kelton, and B. Grexton. 2006. The relationship between herd level disease incidence and a return over feed index in Ontario dairy herds. Can. Vet. J. 47:767-773.

Negussie, E., I. Strandén, and E. A. Mäntysaari. 2008. Genetic analysis of liability to clinical mastitis, with somatic cell score and production traits using bivariate threshold-linear and linear-linear models. Livest. Sci. 117:52-59.

Neuenschwander, T. F.-O. 2010. Studies on disease resistance based on producer-recorded data in Canadian Holsteins. PhD Thesis. University of Guelph, Guelph, Canada.

Olde Riekerink, R. G. M., H. W. Barkema, D. F. Kelton, and D. T. Scholl. 2008. Incidence rate of clinical mastitis on Canadian dairy farms. J. Dairy Sci. 91:1366-1377.
Philipsson, J., and B. Lindhé. 2003. Experiences of including reproduction and health traits in Scandinavian dairy cattle breeding programmes. Livest. Prod. Sci. 83:99-112.

Sargeant, J. M., H. M. Scott, K. E. Leslie, M. J. Ireland, and A. Bashiri. 1998. Clinical mastitis in dairy cattle in Ontario: Frequency of occurrence and bacteriological isolates. Can. Vet. J. 39:33-38.

SAS Institute. 2008. SAS Version 9.2. SAS Institute Inc., Cary, NC.

Urioste, J. I., J. Franzén, and E. Strandberg. 2010. Phenotypic and genetic characterization of novel somatic cell count traits from weekly or monthly observations. J. Dairy Sci. 93:5930-5941.

van Dorp, R. T. E., S. W. Martin, M. M. Shoukri, J. P. T. M. Noordhuizen, and J. C. M. Dekkers. 1999. An epidemiologic study of disease in 32 registered Holstein dairy herds in British Columbia. Can. J. Vet. Res. 63:185-192.

Windig, J. J., W. Ouweltjes, J. ten Napel, G. de Jong, R. F. Veerkamp, and Y. De Haas. 2010. Combining somatic cell count traits for optimal selection against mastitis. J. Dairy Sci. 93:1690-1701. 